they practically have been. For I call it "overlooking" if that most valuable potential asset, a trained medical student, is treated by the State exactly as if he was an ordinary volunteer private so far as capitation allowance and boons and training are concerned. It seems too ridiculous that the State should be unable to perceive that the trained medical student is well worth a high capitation and very special treatment as regards training facilities in view of his future usefulness in war when qualified.

So long as the student is merged in a corps of ordinary volunteer laymen it is impossible to give him special terms and special training; hence it is essential that special student corps be formed with special grants, special officers, special training, and special advantages both while students and after receiving diplomas.

I now, after 25 years, again say in your pages that the true basis of a war reserve is to be found in giving special training to the students and in addition giving them distinct boons if they so train. What then do I suggest? 1. That the senior medical students be entirely removed from the ordinary Royal Army Medical Corps Volunteers and formed into one cadet battalion Royal Army Medical Corps for the three kingdoms, with companies in certain cities? 2. That the student be put to no expense whatever if he joins such a corps. That a capitation grant, full and ample, be given him quite beyond the grant given to the ordinary lay volunteer. Mr. Brodrick, when Minister of War, assured me himself that he thought a \&5 a year capitation quite a moderate one for so valuable a person as a potential doctor. 3 . That a special adjutant and instructors be allowed the cadet battalion. That a special paid commandant from the Royal Army Medical Corps be appointed to it. 4. That in addition to drills and lectures 14 days' field training in three consecutive years be given the students with pay as for the regular army and all expenses of food and transport be paid by the State for the training period in camp. That the uniform be made so similar to Royal Army Medical Corps officers that with a little addition of badges, \&c., the student could wear it when he gets his diploma as a volunteer reserve officer. That special prizes be given by the State to the corps of cadets for efficiency. That in competing for commissions in the Royal Army Medical Corps certain marks be given for efficiency gained in the school companies so that physically fit and mentally active men may join the Royal Army Medical Corps as officers of the regular service. That "under officers" as at the Royal Military Academy at Woolwich be chosen out of the students and be specially compensated for efficiency. That special equipment be given such a company for practice and training. That special facilities to learn to ride be given them. That only physically fit men up to the physical army standards be so trained. That the number be limited and the more senior students be chosen rather than the junior. That expulsion be possible for grave neglects or misdemeanours. That the total number be so framed as to provide for possible army and navy wants in the regular services and a suitable reserve for both services. That in accepting students into the Cadet Battalion, Royal Army Medical Corps, only men who have passed the first half of their professional examinations be accepted. That the recommendations of their teachers be an element in the choice of candidates. That if a student is willing he can go through the 42 days' field training "off the reel" and be set free from further training on passing an examination in the course. That the cadet company allotted to Ireland be treated as a militia company as there are no volunteers in Ireland. That the corps be in number about 300,150 being in London, 50 in Dublin, and 50 in Edinburgh, and sections in the smaller centres of medical education, but all to assemble annually for drill and at a fixed centre like Aldershot in the Long Vacation. That students in the Cadet Battalion who have passed their examination in the military subjects should on getting their diplomas be de facto commissioned in a medical reserve for war for three years, the military subjects to be military hygiene, hospital organisation, drill and discipline of the Royal Army Medical Corps, and army regulations and riding. That it be considered all such cadets should have the status of non-commissioned officers or warrant officers while under training and not that of private volunteers so as to receive a fuller pay rate in camp.

These suggestions endeavour to use our volunteer and militia regulations to specialise the students of medicine at an earlier date for military work and so to prepare for any grave national emergency that may overtake the Empire. All subscriptions from private sources or private volunteers should be unnecessary and the State should provide the total charges, the State to provide headquarters, which should be at or near a military hospital.

$$
\text { I am, Sirs, yours faithfully, }
$$

London, June 2nd, 1906. GEORGE EVATT,

\section{REFORM OF THE ROYAL COLLEGE OF SURGEONS OF ENGLAND.}

\section{7o the Editors of THE LANCET.}

SIRs,-I feel sure that you will allow me to express my amazement at the interpretation which $\mathrm{Mr}$. Tweedy has thought fit to place upon my letter. I should no more think of accusing the College Council of offering a bribe than of accepting one, and I empbatically deny that either explicitly or implicitly I made any such suggestion. To ask a man to dinner is not bribery; during a Parliamentary election it may possibly be "treating," but at ordinary times it is what I said it was, "keeping on the right side" of him. I venture to submit that $\mathrm{Mr}$. Tweedy's indignation is a little overdone. He knows the con. stitutional history of the College probably better than any man living; he therefore knows that again and again in the past the efforts of reformers have been thwarted by the influence-possibly the legitimate influence-of members of the Council with the powers that be-viz., the Government of the day. Would it be so very extraordinary if this influence were once more exercised? Mr. Tweedy has, in his well-known pamphlet, quoted with approval the dictum of THE LANCET that the Charter of 1843, which still determines the constitution of the College, was-like that of 1800 - "obtained by misrepresentation and fraud." $\mathrm{He}$ is not therefore surprised at the agitation among the Members for restitution of their ancient rights, which he describes in the same pamphlet as a "late manifestation of an abiding resentment."

This resentment has been intensified by the action of the Council, which has treated the Members' proposals with contemptuous indifference, returning the same stereotyped reply year after year. Is it therefore to be wondered at that some such proposal as a professional boycott should have been made, since the Members are in all College matters systematically boycotted by the Council? No one will be more distressed than I should things reach such a pitch and although the proposal has been urged upon us for years we have never before publicly referred to it. As to whether it be more "immoral "than the present attitude of the Council towards the Members' claims opinions will, no doubt, differ, but if adopted it would prove to be anything but "ridiculous." If the Council measure the interest taken in this question by the attendance at the annual meetings they are making a very serious mistake.

June 4th, 1906

I am, Sirs, yours faithfully, W. G. DICKINSON.

\section{THE TREATMENT OF ASCITES.} To the Editors of THE LANCET.

SIRs,-I have read an account of a case of ascites, which was tapped 69 times, reported by Mr. Frederick H. Maberly in The LANCET of April 21st, p. 1108. The case is interesting and instructive when the amount of fluid which must have been removed during the repeated tappings is considered. I am deeply interested in the mention of a belt used by the patient and would like some further information on this point. I have on several occasions seen cases treated by Dr. Alexander Morison where the re-accumulation of the fluid has been prevented by the use of plaster strapping applied after the tapping of the ascitic fluid. I have been struck by the great value of the simple and apparently overlooked procedure in the treatment of ascites.

In one patient who was under my care suffering from tuberculous peritonitis with a large accumulation of fluid the above line of treatment was carried out without the preliminary tapping and the support given by the repeated strapping did away with the necessity for tapping. The patient made a good recovery and two years afterwards was reported as being quite well.

A second case was that of a woman, aged 45 years, the subject of alcoholic cirrhosis of the liver with ascites. She made 
excellent progress when treated by a preliminary tapping and plaster strapping over the entire abdomen bat it was found impossible to continue the strapping on account of the irritation produced on the skin of the abdomen. In this case I used an abdominal belt with a rigid anterior surface, under which I placed a large indiarubber pad internally; the pad occupied the whole surface of the belt, it had a small stop-cock attached, through which air could be pumped at pleasure. The internal pressure of the pad could be increased or diminished at will. The patient made a good recovery and up to the present date (one year after treatment ceased) has had no recurrence of ascites and is in good health. No improvement took place in the patient's condition until the pressure was applied; indeed, up to the time when it was commenced the fluid had been gradually accumulating and the patient was just on the point of being tapped for the second time when the pressure was applied. 'The immediate effect of the application of pressure was a gradual and steady increase of the daily output of urine and a steady diminution in the quantity of fluid in the abdominal cavity. When she was last seen there was no fluid to be detected in the abdomen.

I trust you will pardon the narration of this case at such length but $I$ think it well to quote this method of treatment which, in Dr. Morison's hands, has met with such marked success.

In Mr. Maberly's case the use of the belt does not appear to have reduced the quantity of fluid, but I note he quotes its use as being a support of the abdominal walls and possibly the pressure employed may not have been sufficient to have increased the intra-abdominal pressure, a very important point in the treatment of all cases of ascites where the object of the use of any form of abdominal pressure should be to promote the absorption of fluid by giving the lymphatic system the help it so greatly needs in the disposal of the excessive accumulation of fluid. I am, Sirs, yours faithfully,

Highgate, June 1st, 1906. ROBERT KNox, M.D. Edin.

\section{PROPOSED AMALGAMATION OF THE LONDON MEDICAL SOCIETIES :}

\section{A DISCLAIMER.}

To the Editors of THE LANCET.

SIRS,-Referring to the letter which appeared in your issue of March 17th, p. 789, I wish to say with regard to Mr. Goodsall's statement that, although I have no definite recollection of my conversation with him, he has recalled the circumstances of his visit to me, and I have no doubt that I expressed the opinion that the building was good for at least another 50 years. Mr. Goodsall was evidently under the impression at that time that I was engaged professionally upon the structural alterations when the Royal Medical and Chirurgical Society took possession. This, howerer, was not so. Now that I have examined the structure $I$ have no hesitation in stating that it is thoroughly sound and should last as long as any other erection of its age and class in London.

I am, Sirs, yours faithfully,

Hanover-square, London, W., June 1st, 1906. JoHN BELCHER.

\section{MEDICINE IN THE SOUDAN.}

Io the Editors of THE LANCET.

Sins, - The vast expanse of territory known as the Soudan can only be regarded as in its infancy. The population a few years ago was variously estimated at from 8,500,000 to $15,000,000$, but owing to the disastrous Dervish rule under the Mahdi and his successor it is at present believed to be less than $2,000,000$. There is every reason, however, to hope for a rapid improvement in this respect, one of the most encouraging points being the very large proportion of young children to be met with in most of the provinces. In Dongola the number of children under nine years of age is estimated at 43,000 , or 32 per cent. of the total inhabitants. Under the head of public health in Lord Cromer's last report, which you have already reviewed, it is stated that the campaign against malaria is being continued throughout the country. Vaccination is being vigorously pushed, at least 50,000 individuals having being vaccinated last year against 12.000 in 1904 and about 7000 in 1903

Dr. J. B. Christopherson, the head of the civil medical department, writes hopefully about the public health in Lord
Cromer's report: "It is possible" he says, "to strike a cheerful chord this year. The Soudan is not the feverstricken, small-pox ravaged country into which the Egyptian diseases (ophthalmia, bilharzia, and anchylostoma), are rapidly being introduced, while sleeping sickness is advancing, cholera and plague threatening Port Soudan, and leprosy creeping in from the West. What are the facts? There are five provinces at least which are practically free from the malaria infection-fever cannot originate there-namely, Halfa, Dongola, Berber Khartoum, and Suakin; and, with the introduction of suitable dwellings and energetic mosquito brigades, other provinces will be freed from malaria. Small-pox shows itself occasionally, but if the country can be vaccinated throughout small-pox will disappear. Great advances towards this end have been made during the last year or two. The carrier of sleeping sickness bas been caught in Soudan territory, it is true, but so far not a single case of sleeping sickness has been imported. Quarantine regulations have been instituted for Port Soudan and for the Soudan generally; and the arrangements at Halfa have been so far svc essful that plague and cholera have been kept out. Fgyptian ophthalmia is decidedly uncommon, and bilharzia and anchylostoma, the two principal Egyptian diseases, have not taken hold of the natives to any extent. Lastly, the natives are amenable to medical treatment, so that there is little difficulty in carrying out measures for the security of the country against epidemics so far as active opposition from the people is concerned." "It is satisfactory," adds Lord Cromer, "to know that the natives of the country are gradually gaining confidence in the hospitals. A native correspondent recently wrote to the soudan Times in the following terms: "A few years back the arrival of a medical officer in a village meant a general alarm; everybody sought a hiding place. Now, things have changed in such a manner that native patients flock to the hospitals to be treated."

The passages which I have quoted seem to me to bear striking testimony to the fact that scientific medicine will form one of the strongest bonds of international union in the future. I am, Sirs, yours faithfully,

May 25th, 1906. A Traveller,

\section{BIRMINGHAM.}

(FROM OUR OWN CORRESPONDENT.)

\section{The University Library and the Medical Institute.}

THE University library contains a very valuable selection of books and periodicals dealing with scientific subjects associated with medicine-that is, with anatomy, physiology, and pathology, but these have not hitherto been at the disposal of the practitioners of the city and neighbourhood except by special permission. On the other hand, the library of the Medical Institute is well provided with current medical literature which could only be consulted by members of the University staff, who were not members of the institute, after application to the authorities of the institute. The periodicals and the books possessed by the University and the institute are complementary to each other and now and then occasions arise when the members of one institution desire to consult the books or periodicals possessed by the other. Permission for such consultation has never been denied, so far as I am aware, but delay may occur in obtaining it. Therefore, it was suggested that the libraries of the two institutions should be open to the members of both on con. dition that each member using the library of the institution to which he does not belong shall sign his name and address in a book kept for the purpose. This suggestion was put in a concrete form at a meeting of representatives of both institutions. I understand that it has now been agreed to by the library committees of both the University and the Medical Institute and that the necessary instructions have been given to the librarians. The arrangement is most welcome, for it extends the scope of each library very considerably.

\section{Infant School Reform.}

If our race is to be continued not only as strong and healthy as it has been but also improved then there is no doubt that careful attention must be given to our young children and it is essential that the natural growth of their 